\title{
Effect of Short Fiber Reinforcement on Mechanical Properties of Hybrid Phenolic Composites
}

\author{
Sembian Manoharan, ${ }^{1}$ Bhimappa Suresha, ${ }^{2}$ \\ Govindarajulu Ramadoss, ${ }^{3}$ and Basavaraj Bharath ${ }^{4}$ \\ ${ }^{1}$ Department of Mechanical Engineering, SSM College of Engineering, Komarapalayam, Tamil Nadu 638183, India \\ ${ }^{2}$ Department of Mechanical Engineering, The National Institute of Engineering, Mysore, Karnataka 570 008, India \\ ${ }^{3}$ Department of Mechanical Engineering, Shivani College of Engineering and Technology, Trichy, Tamil Nadu 620009, India \\ ${ }^{4}$ Department of Automobile Engineering, Sri Jagadguru Mallikarjuna Murugharajendra Institute of Technology, \\ Chitradurga, Karnataka 577 502, India
}

Correspondence should be addressed to Bhimappa Suresha; sureshab2004@yahoo.co.in

Received 23 February 2014; Revised 31 May 2014; Accepted 4 July 2014; Published 6 August 2014

Academic Editor: Andrzej Galeski

Copyright (C) 2014 Sembian Manoharan et al. This is an open access article distributed under the Creative Commons Attribution License, which permits unrestricted use, distribution, and reproduction in any medium, provided the original work is properly cited.

Fiber plays an important role in determining the hardness, strength, and dynamic mechanical properties of composite material. In the present work, enhancement of viscoelastic behaviour of hybrid phenolic composites has been synergistically investigated. Five different phenolic composites, namely, $\mathrm{C} 1, \mathrm{C} 2, \mathrm{C} 3, \mathrm{C} 4$, and $\mathrm{C} 5$, were fabricated by varying the weight percentage of basalt and aramid fiber, namely, $25,20,15,10$, and $5 \%$ by compensating with barium sulphate $\left(\mathrm{BaSO}_{4}\right)$ to keep the combined reinforcement concentration at $25 \mathrm{wt} \%$. Hardness was measured to examine the resistance of composites to indentation. The hardness of phenolic composites increased from 72.2 to 85.2 with increase in basalt fiber loading. Composite $\mathrm{C} 1$ ( $25 \mathrm{wt} \%$ fiber) is 1.2 times harder than composite C5. Compression test was conducted to find out compressive strength of phenolic composites and compressive strength increased with increase in fiber content. Dynamic mechanical analysis (DMA) was carried out to assess the temperature dependence mechanical properties in terms of storage modulus $\left(E^{\prime}\right)$, loss modulus $\left(E^{\prime \prime}\right)$, and damping factor $(\tan \delta)$. The results indicate great improvement of $E^{\prime}$ values and decrease in damping behaviour of composite upon fiber addition. Further X-ray powder diffraction (XRD) and energy-dispersive X-ray (EDX) analysis were employed to characterize the friction composites.

\section{Introduction}

The brake system of an automobile is an inevitable safety aspect, which stops the vehicle quickly and reliably under varying conditions. Nowadays nonasbestos organic (NAO) friction materials are mainly used in automotive brake linings and it is a mixture of four classes of ingredients, namely, binder, reinforcements, fillers, and friction modifiers $[1,2]$. Among these ingredients, organic binder (phenol formaldehyde) plays a crucial role in determining the characteristics of material during braking and holds all other ingredients together. Fibers (mineral, aramid, glass, carbon, ceramic, and steel wool) are used to improve the strength of composite, while fillers are mainly used to bring down the cost and act as lubricants and abrasives to control wear rate of the composite. This multicomponent nature of friction composite helps the brake lining material to withstand very high pressure and thermal stresses and contribute to an effective braking performance $[3,4]$. The fiber reinforcement is proved to be potentially promising on tribological properties and forms the basis for formulating the brake friction material. Basalt is a kind of alumina silicate fiber composed of many oxides with high strength, heat insulating properties, and good fiber/resin interfacial bonding [5]. Phenol formaldehyde resin is popular in the resin-based friction material, because it is superior in the heat resistance, mechanical properties, forming performance, and cost. If polymer composite is subjected to harsh environmental conditions, the material performance 
becomes more critical because of viscoelastic nature. These viscoelastic properties can be completely described over a range of time, temperature, and frequency by dynamic mechanical analysis (DMA). In general, DMA is the most sensitive way to measure the subtle transition phases and glass transition temperature $\left(T_{g}\right)$ of composite. The properties of polymer change when the material is heated through glass transition temperature and undergoes glass/rubbery state transition. To assure better structural applications, the applied temperature has to be less than that of glass transition temperature of composites [6,7]. Kumaresan et al. [8] conducted DMA in silicon carbide $(\mathrm{SiC})$ filled carbonepoxy composites and stated that storage modulus $\left(E^{\prime}\right)$ and glass transition temperature were found to increase with filler loading. Sreekala et al. [9] investigated viscoelastic behaviour of oil palm/glass fiber reinforced phenol formaldehyde (PF) composite and revealed that storage modulus $\left(E^{\prime}\right)$ and damping factor $(\tan \delta)$ show great enhancement upon fiber addition. Wagge et al. [10] analysed the effect of incorporation of various fillers on curing process of a phenol formaldehyde resin by DMTA and stated that the curing process of composite was not affected by filler addition. Wang et al. [11] studied the failure mechanism and thermomechanical properties of fibre/filler reinforced phenolic matrix composites and reported that filler-matrix debonding is the primary failure mechanism of composites above $360^{\circ} \mathrm{C}$. Nair et al. [12] studied DMA on sisal fiber reinforced polystyrene (PS) composites and stated that $10 \%$ fiber loading increases the dynamic modulus values considerably. Saha et al. [13] studied dynamic mechanical investigations on chemically modified jute fibre and polyester composites and concluded that chemically treated fiber improves storage modulus and thermal transition temperature of the composites. Investigation of dynamic mechanical properties, dynamic modulus, and internal friction over a wide range of temperature is useful in studying the polymer composite structure. Wu et al. [14] studied the dynamic mechanical thermal analysis (DMTA) along with friction test and reported that glassrubber transition of thermosetting resin significantly influences the friction and wear behaviour of composite materials. During braking, a compressive force acts on the friction composites; hence, these composites should have high compressive strength in order to eliminate the failure under applied braking pressure. Thus it is necessary to understand the compressive strength of friction composites. Talegaonkar and Gopinath [15] conducted the compressive strength of friction composites and concluded that compressive strength of composite increased with increase in alumina fiber content.

By reviewing the above said literature, it was decided that in order to study the mechanical properties in this present work hybrid fiber reinforced friction composite was fabricated by varying the relative weight fraction of basalt and aramid fiber, namely, $5,10,15,20$, and $25 \%$, by compensating with $\mathrm{BaSO}_{4}$ to keep the concentration at $25 \%$. The fabricated phenolic composites were characterized using dynamic mechanical analysis (DMA), mechanical properties, $\mathrm{X}$-ray powder diffraction (XRD), and energy-dispersive Xray (EDX) analysis.

\section{Experimental Procedure}

A phenol formaldehyde powder $(9.2 \mathrm{wt} \%$ hexamethylenetetramine, Claro chemicals, Chennai) along with cashew nut shell liquid (CNSL), plaster of paris, and carbon powder were used as binder. Basalt fiber (Muktagiri Industrial Corporation, Mumbai, average fiber diameter of $15 \mu \mathrm{m}$, length of up to $6 \mathrm{~mm}$ ) and recycled aramid short fibers (Sathya Cashew Chemical Ltd., Chennai, average fiber length of up to $2 \mathrm{~mm}$ ) were used as reinforcements. Molykote, copper powder $(\mathrm{Cu})$, iron powder $(\mathrm{Fe})$, silicon carbide $(\mathrm{SiC})$, alumina $\left(\mathrm{Al}_{2} \mathrm{O}_{3}\right)$, cashew friction dust, and barium sulphate $\left(\mathrm{BaSO}_{4}\right)$ were added as fillers in the friction composite. The ingredients of phenolic composite (in wt\%) are listed in Table 1. The composite sample code used for these composites represents the volume of fiber contents.

2.1. Fabrication of Phenolic Composites. The fabrication of composite containing thirteen ingredients as listed in Table 1 and this process consists of series of operations including mixing, hydraulic pressing, curing, postcuring, and finishing as shown in Figure 1. In order to obtain the homogeneous mix, the sequence and time of mixing were maintained properly. The proper proportions of the various ingredients were blended in a laboratory mixer. Initially the fibers (basalt and aramid) are mixed together for $5 \mathrm{~min}$ and then the filler particles were added with further mixing for about $10 \mathrm{~min}$. Finally the phenol formaldehyde based binder was added and final mixing was carried out for another $5 \mathrm{~min}$. After mixing operation, the phenolic composites were fabricated using hot compression moulding technique. In compression moulding, the mould and die were initially preheated up to $80^{\circ} \mathrm{C}$ and cleaned by a thin layer of soap water (which acts as a barrier between the composite and the mould cavity). After preheating, the mould cavity was filled with composite mixture and then adhesive coated back plate was placed on the mould in order to maintain a secure bonding between friction composite and plate. The assembly was subjected to hot pressing at a pressure of 40 ton, following the curing cycle as shown in Figure 2. After curing, the composite block was removed from the mould and postcured at $120^{\circ} \mathrm{C}$ for $60 \mathrm{~min}, 150^{\circ} \mathrm{C}$ for $60 \mathrm{~min}$, and $170^{\circ} \mathrm{C}$ for $120 \mathrm{~min}$, respectively. Curing refers to the toughening or hardening of a composite made from several different materials. This is achieved using chemical additives or heat or with the use of ultraviolet radiation. In the present study, the postcuring process helps in giving a stronger, more reliable product which can be produced more efficiently and cost effectively. Postcuring operation was done to cure the residual resin. Also it increases the amount of cross-linking of polymer to achieve better chemical and mechanical properties and heat resistance. The postcuring apparatus is shown in Figure 3 . Finally the composite block of size $20 \mathrm{~mm} \times 20 \mathrm{~mm} \times 6 \mathrm{~mm}$ was removed from mould and the required size of sample was prepared according to experimental work. Test samples for various experiments were prepared from the friction composites using abrasive cut off machine according to ASTM standard. 
TABle 1: Design of the formulation.

\begin{tabular}{|c|c|c|c|c|c|c|}
\hline \multicolumn{7}{|c|}{ Ingredients (wt\%) } \\
\hline Composite designation & & Fibers & Binder & Fillers & & Total \\
\hline Sample & Basalt & Aramid (recycled) & $\begin{array}{l}\text { Phenol formaldehyde powder } \\
(17 \mathrm{wt} \%) \text {, cashew nut shell } \\
\text { liquid (CNSL, } 9.5 \mathrm{wt} \%) \text {, } \\
\text { plaster of paris (1.5 wt } \%) \text {, and } \\
\text { carbon black ( } 2 \mathrm{wt} \%)\end{array}$ & $\begin{array}{c}\text { Molykote (11 wt\%), copper }(\mathrm{Cu} \text {, } \\
7 \mathrm{wt} \%) \text {, iron }(\mathrm{Fe}, 7 \mathrm{wt} \%) \text {, silicon } \\
\text { carbide ( } \mathrm{SiC}, 4 \mathrm{wt} \%) \text {, alumina }\left(\mathrm{Al}_{2} \mathrm{O}_{3} \text {, }\right. \\
5 \mathrm{wt} \%) \text {, and cashew friction dust }(11 \%)\end{array}$ & $\mathrm{BaSO}_{4}$ & \\
\hline $\mathrm{C} 1$ & 20 & 5 & 30 & 45 & 0 & 100 \\
\hline $\mathrm{C} 2$ & 15 & 5 & 30 & 45 & 5 & 100 \\
\hline $\mathrm{C} 3$ & 10 & 5 & 30 & 45 & 10 & 100 \\
\hline $\mathrm{C} 4$ & 5 & 5 & 30 & 45 & 15 & 100 \\
\hline C5 & 5 & 0 & 30 & 45 & 20 & 100 \\
\hline
\end{tabular}

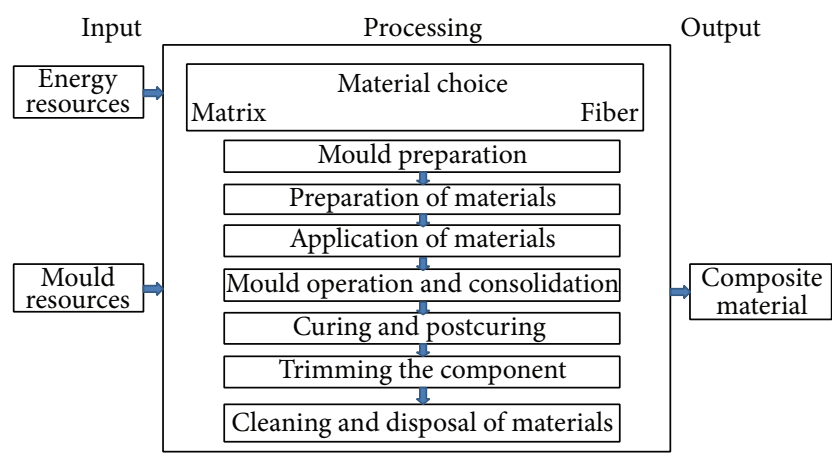

FIGURE 1: Layout of manufacturing process hybrid friction composites.

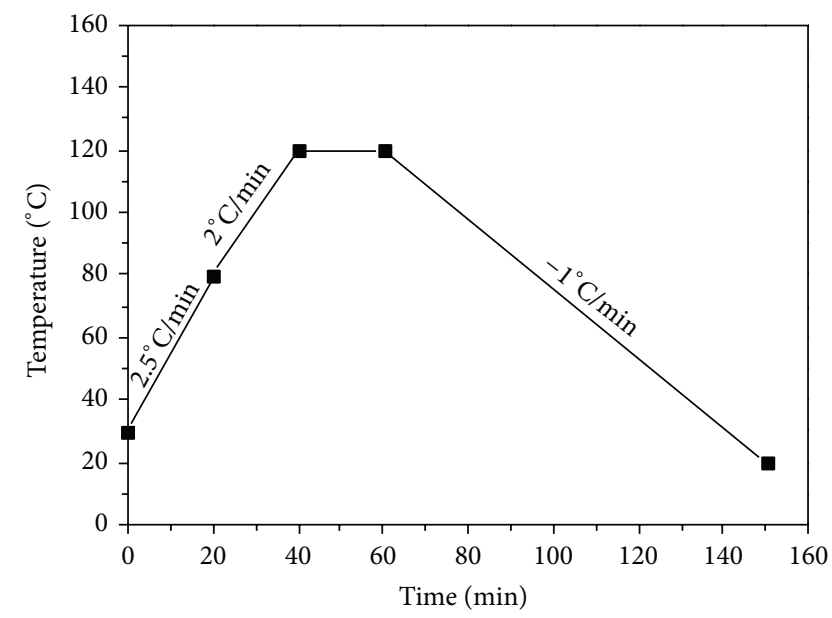

FIgURE 2: Curing cycle of hybrid friction composites.

\section{Characterization of Phenolic Composite}

3.1. Physicomechanical Properties. The physical and mechanical characterization of the polished friction composite samples such as their density, hardness, and compressive strength are presented in Table 2. Density of phenolic composite was determined using a high precision (Mettler; Toledo) weighing balance by using the Archimedes principle. The hardness of

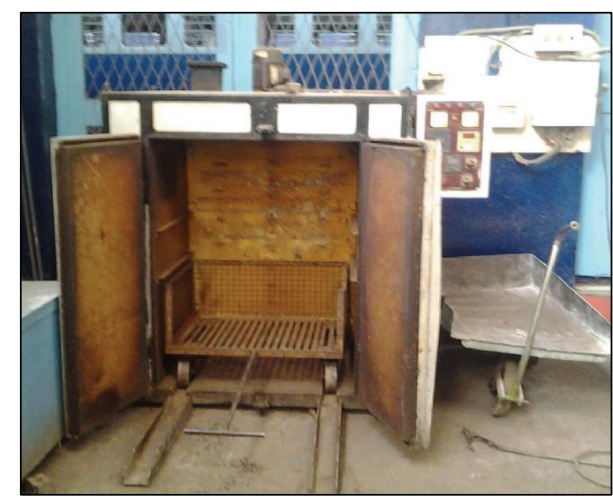

FIGURE 3: Postcuring apparatus.

the composites were measured by shore D hardness tester (HT-6510D, Korean make) according to ASTM standard of D2240-00. The hardened steel rod with $1.4 \mathrm{~mm}$ diameter, $30^{\circ}$ conical point, and $0.1 \mathrm{~mm}$ radius tip was used to measure the depth of indentation by applying a load of $45 \mathrm{~N}$. A test specimen size $50 \mathrm{~mm} \times 50 \mathrm{~mm} \times 6 \mathrm{~mm}$ was used to measure the hardness of phenolic composites. To know about compressive strength of composite, compression test (specimen size $=25 \mathrm{~mm}$ length and $12.5 \mathrm{~mm}$ diameter cylindrical pin, speed $2 \mathrm{~mm} / \mathrm{min}$, and load range of $10 \mathrm{kN}$ ) was carried out using Kalpak universal testing machine (Model KIC, serial number 121101) according to ASTM standard of D695.

3.2. Dynamic Mechanical Analysis. Dynamic mechanical analyzer (DMS 6100, SII Nano Technology, Japan) was used to characterize the storage modulus $\left(E^{\prime}\right)$, loss modulus $\left(E^{\prime \prime}\right)$, and damping factor $(\tan \delta)$ in the temperature range of $28^{\circ} \mathrm{C}$ and $285^{\circ} \mathrm{C}$, at a frequency of $1.0 \mathrm{~Hz}$ and heating rate of $2^{\circ} \mathrm{C} / \mathrm{min}$. The dimensions of the composite sample were $40 \times$ $10 \times 3.5 \mathrm{~mm}^{3}$ and measurements were done according to ASTM standard D 4065-01 using dual cantilever bending mode.

3.3. X-Ray Diffraction Analysis. X-ray diffraction (XRD) analysis was carried out using X-ray diffractometer (XRD 6000, SHIMADZU, Japan) with $\mathrm{CuK}_{\alpha}$ as a radiation source 
$(\lambda=0.154 \mathrm{~nm})$. The samples were scanned at diffraction angles $(2 \theta)$ between 5 and $90^{\circ}$ at a scanning rate of $0.2^{\circ}$ per minute.

3.4. Energy-Dispersive X-Ray Analysis. Elemental detection via electron dot-mapping was conducted using energydispersive X-ray (EDAX) analysis on the scanning electron microscope (SEM; JEOL make 840 Model, Japan).

\section{Results and Discussion}

4.1. Density, Hardness, and Compression Strength. Table 2 shows the measured density and hardness of phenolic composites. The hardness of phenolic composites increased from 72.2 to 85.2 with increase in basalt fiber content. Composite $\mathrm{C} 1$ with higher amount of basalt fiber is 1.2 times harder than composite $\mathrm{C} 5$. The increase in hardness might be attributed to higher hardness of basalt fiber, hard ceramic, and metallic particles. Moreover, relatively uniform distribution of all phases and decreased interparticle distance within the matrix result in increased resistance of composites to indentation. Compressive strength of phenolic composites increased with increase in fiber content. Composite with higher fiber content (C1, $25 \mathrm{wt} \%$ fiber) showed maximum compressive strength than that of other composites. This is attributed to the fact that increase in fiber content increases the micro-packing of fibers in the cured network of phenol formaldehyde matrix, that causes mechanical compaction of the fibrous ingredients which shows effective synergism.

4.2. Dynamic Mechanical Analysis. The viscoelastic behaviour indicates the macroscopic consequences of molecular movements. In polymers, molecular mobility is a function of temperature which in turn affect dynamic modulus and damping factors. In general, dynamic modulus and damping factors are used to describe the interfacial interaction in composites.

4.2.1. Storage Modulus. Viscoelastic storage modulus $\left(E^{\prime}\right)$ is a measure of stiffness of a composite and also represents the energy stored in sinusoidal stressed sample which is shown in Figure 4. It illustrates the effect of temperature on storage modulus of composite samples and storage modulus versus temperature curve is potentially promising in measuring the stiffness, degree of cross linking and fiber/matrix interfacial bonding of material under investigation [16]. The storage modulus curve exhibits three temperature-dependent transition regions, such as a low temperature glassy region, a drastic modulus drop region which corresponds to respective relaxation in matrix and indicates the material is going through glass/rubbery state transition, and a high temperature rubbery plateau [17]. The $E^{\prime}$ value of composite samples decreases with temperature and increases with increase in weight fraction of basalt fiber content. The $E^{\prime}$ tends to become broader in glassy region and the modulus values follows the trend of $E^{\prime} \mathrm{C} 1>E^{\prime} \mathrm{C} 2>E^{\prime} \mathrm{C} 3>E^{\prime} \mathrm{C} 4>E^{\prime} \mathrm{C} 5$. This is due to the fact that basalt fiber reinforcement increases the matrix capacity to support mechanical constraints with recoverable deformation which shifts $T_{g}$ to higher temperature, that is, from $154^{\circ} \mathrm{C}$ of composite C5 to $186^{\circ} \mathrm{C}$ of composite $\mathrm{C} 1$. In glassy region, ingredients are in frozen state (immobile), close, and tightly packed resulting in high storage modulus value below $T_{g}$ [18]. As the temperature increases the components tend to show increased molecular mobility, hence, lose their tight packing arrangement which gradually decreased the $E^{\prime}$ values in rubbery region. Thus microBrownian movement of polymeric composites at temperature near $T_{g}$ decreases the storage modulus value [17]. The $E^{\prime}$ curves suffer an intense drop around $150^{\circ} \mathrm{C}$ which indicates glass/rubbery state transition. Then it gradually increases after passing maximum; the $E^{\prime}$ again tends to decrease. It is clear that the rise of $E^{\prime}$ is the expected outcome of crosslinking process that is, temperature around $200^{\circ} \mathrm{C}$. It is the point where cross-linking process takes place without any vitrification. After that it attains final drop above $250^{\circ} \mathrm{C}$ where cross-linking induced vitrification leads to plateau of $E^{\prime}$ in rubbery region. Vitrification appears when glass transition temperature $\left(T_{g}\right)$ of cross-linked polymer reaches the curing temperature [19]. The $E^{\prime}$ is influenced by inherent stiffness of fiber which allows effective stress transfer between fiber and matrix and directly proportional to interfacial bonding [20]. Figure 4 delineates that composite $\mathrm{C} 1$ with high $E^{\prime}$ value has better interfacial bonding and improved mechanical stability at higher temperature than other composites. The reinforcement effectiveness $(r)$ on the modulus of composite was estimated as the ratio of moduli in glassy to rubbery region for composite to that of matrix, that is, $r=\left(E^{\prime} 28^{\circ} \mathrm{C} / E^{\prime} 265^{\circ} \mathrm{C}\right)$ composite $/\left(E^{\prime} 28^{\circ} \mathrm{C} / E^{\prime} 265^{\circ} \mathrm{C}\right)$ resin, where $E^{\prime} 28^{\circ} \mathrm{C}$ and $E^{\prime}$ $265^{\circ} \mathrm{C}$ are assumed to be moduli corresponding to glassy $\left(E^{\prime} @ 28^{\circ} \mathrm{C}\right)$ to the rubbery $\left(E^{\prime} @ 265^{\circ} \mathrm{C}\right)$ regions, respectively. The values of $(r)$ obtained for fabricated composite sample are listed in Table 3. The lower the coefficient $(r)$ value is, the higher the fiber effectiveness is [21]. It was found that with increase in basalt fiber loading, the magnitude of coefficient decreases, indicating better fiber effectiveness.

4.2.2. Loss Modulus. Loss modulus $\left(E^{\prime \prime}\right)$ is a measure of energy dissipated as heat per cycle under deformation which can be qualitatively measured from the area under loss modulus curves. It is an indication of dispersed relaxation mechanism and also shows similar trend as in the case of storage modulus with variation in relative weight fraction basalt fiber. Figure 5 depicts the effect of temperature on $E^{\prime \prime}$ of composite samples and $E^{\prime \prime}$ values suffer a reduction with decrease in volume fraction of basalt fiber. It follows the trend of $E^{\prime \prime} \mathrm{C} 1>E^{\prime \prime} \mathrm{C} 2>E^{\prime \prime} \mathrm{C} 3>E^{\prime \prime} \mathrm{C} 4>E^{\prime \prime} \mathrm{C} 5$ indicating that sample $\mathrm{C} 1$ with high wt\% of basalt fiber exhibits maximum $E^{\prime \prime}$ value due to increase in internal friction that enhances energy dissipation [22]. Increase in basalt fiber loading causes broadening of loss modulus peak and it is attributed to the fact that the polymer matrix surrounding the fiber is in different physical state to the rest of matrix, which reduces the molecular mobility [23]. The temperature where $E^{\prime \prime}$ was maximum indicates the $T_{g}$ of loss modulus curve [24] and values are given in Table 3. From the table it is clear that $T_{g}$ obtained from $E^{\prime \prime}$ is lower and more realistic than that from 
TABLE 2: Physical and mechanical properties of friction composites.

\begin{tabular}{lccccc}
\hline Composites/properties & $\mathrm{C} 1$ & $\mathrm{C} 2$ & $\mathrm{C} 3$ & $\mathrm{C} 4$ & $\mathrm{C}$ \\
\hline Density $\left(\mathrm{g} / \mathrm{cm}^{3}\right)$ & 1.76 & 1.82 & 1.82 & 1.83 & 1.84 \\
Hardness (Shore D) & 85.2 & 84.4 & 80.5 & 79.6 & 72.2 \\
Compressive strength $(\mathrm{MPa})$ & 66.96 & 54.32 & 43.89 & 31.77 & 24.92 \\
\hline
\end{tabular}

TABLE 3: Peak height of $\tan \delta$ and glass transition temperature $\left(T_{g}\right)$ of hybrid friction composites.

\begin{tabular}{lcccc}
\hline $\begin{array}{l}\text { Composite } \\
\text { designation }\end{array}$ & $\begin{array}{c}\text { Reinforcement } \\
\text { effectiveness coefficient }(r)\end{array}$ & Peak height of $\tan \delta$ & $T_{g}$ from $\tan \delta_{\max }$ & $T_{g}$ from $E^{\prime \prime}{ }_{\max }$ \\
\hline C1 & 2.4 & 0.1 & 187 & 182 \\
C2 & 3.6 & 0.16 & 192 & 175 \\
C3 & 3.4 & 0.14 & 185 & 172 \\
C4 & 4.6 & 0.13 & 155 & 160 \\
C5 & 8.2 & 0.21 & 150 \\
\hline
\end{tabular}

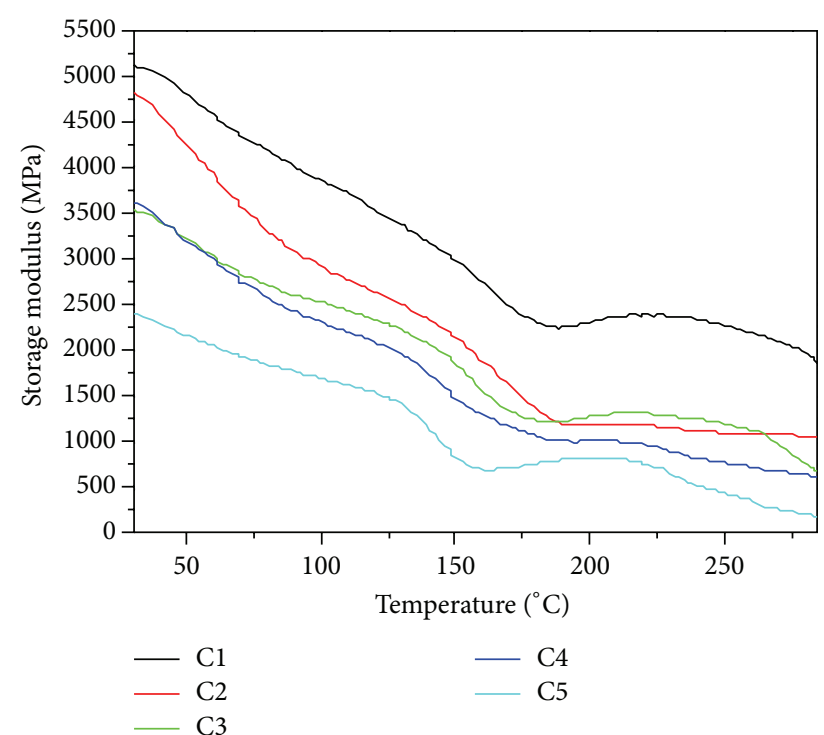

FIGURE 4: Variation of storage modulus $\left(E^{\prime}\right)$ as a function of temperature.

damping factor curves [25] and $E^{\prime \prime}$ in transition was higher for composite $\mathrm{C} 1$ compared to other composites which may be due to higher amount of fibre reinforcement increases the internal friction that enhances energy dissipation [26]. The $T_{g}$ gets shifted to higher temperature, that is, from $150^{\circ} \mathrm{C}$ of composite $\mathrm{C} 5$ to $182^{\circ} \mathrm{C}$ of composite $\mathrm{Cl}$, which may be due to basalt fiber concentration and increased fibre/matrix adhesion. This shift in $T_{g}$ of polymer matrix indicates a strong interaction of fiber with phenolic matrix, by restricting molecular mobility, and gives credence to the role of fiber. In a similar work carried out by Botev et al. [27] on basalt fiber reinforced polypropylene composite, the storage modulus and loss modulus are strongly influenced by basalt fiber content.

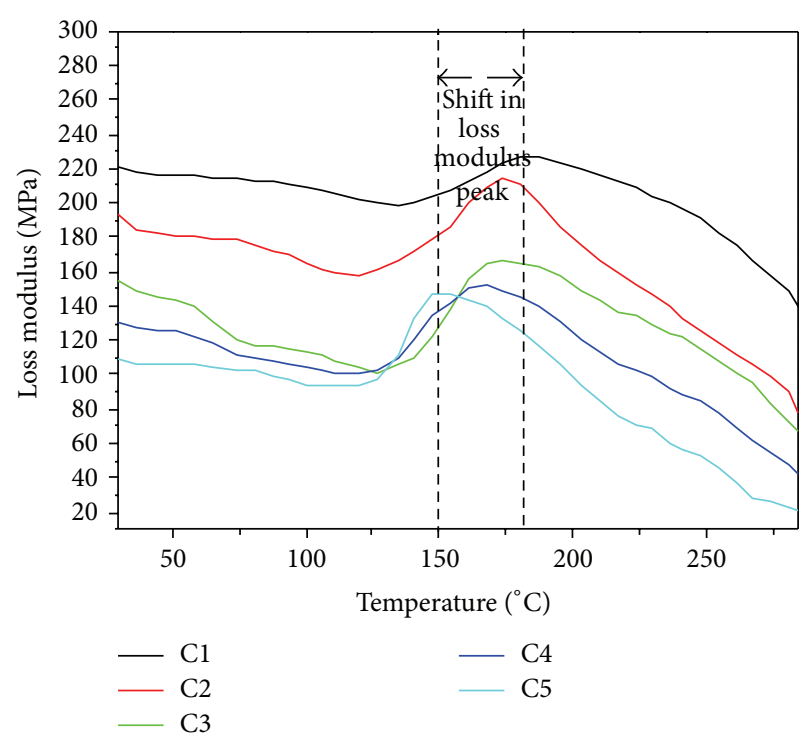

FIGURE 5: Variation of loss modulus $\left(E^{\prime \prime}\right)$ as a function of temperature.

4.2.3. Damping Factor. The magnitude of damping factor $(\tan \delta)$ is an indication of balance between elastic and viscous phase in a polymeric material [26]. The fibre/matrix interfacial adhesion and curing behaviour of composite can be determined from damping curves and its peak represents the glass transition temperature $\left(T_{g}\right)$ of the material. Figure 6 illustrates the variation of damping parameters $(\tan \delta)$ with temperature and shows that damping factor increases with increase in temperature and goes at maximum level in transition region and decreases in rubbery region. It is observed that damping factor is low below $T_{g}$ in all samples because at this stage chain segments are in frozen state. As temperature increases the chain segments become more mobile which results in increased damping factor. Therefore the higher the $\tan \delta$ peak value is, the greater the degree of 


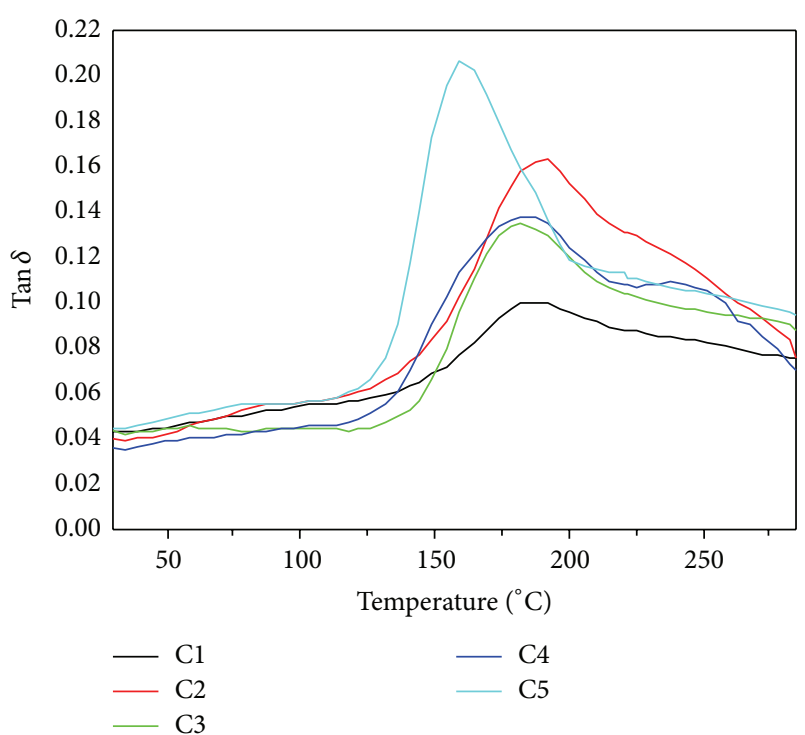

FIGURE 6: Variation of damping factor $(\tan \delta)$ as a function of temperature.

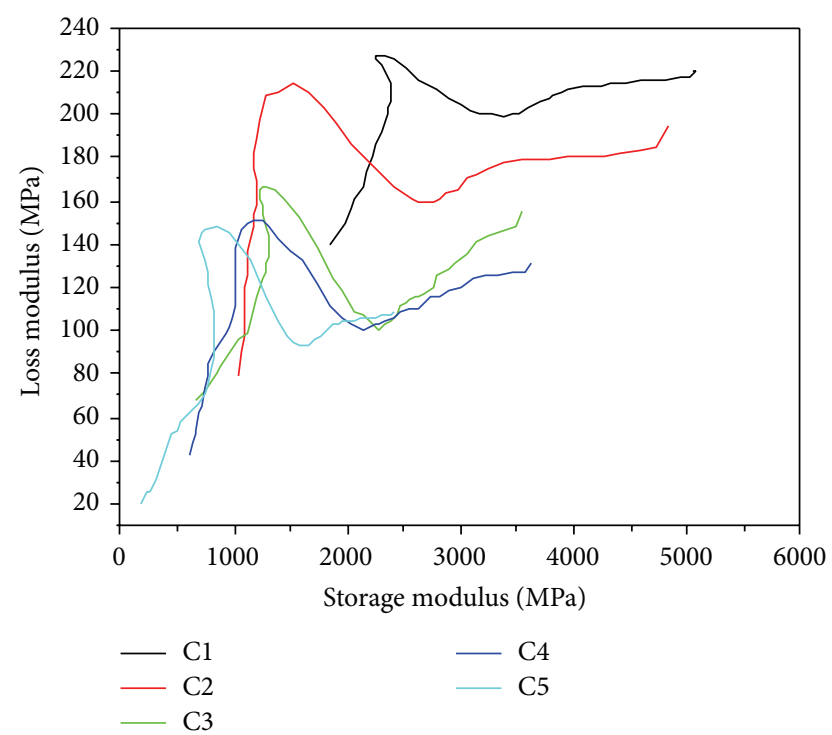

FIgURE 7: Cole-Cole plot of hybrid friction composites.

molecular mobility is [28]. The composites with poor interfacial bonding dissipate more energy, thus producing high damping peak compared to material with strongly bonded interface. The trend in $\tan \delta$ values are $\mathrm{C} 5>\mathrm{C} 4>\mathrm{C} 3>\mathrm{C} 2>\mathrm{C} 1$, which signify that lower $\tan \delta$ value is associated with better interaction between dispersed phase with matrix phase of composites [21]. The $T_{g}$ gets shifted to higher temperature, that is, from $155^{\circ} \mathrm{C}$ of composite $\mathrm{C} 5$ to $187^{\circ} \mathrm{C}$ of composite $\mathrm{C} 1$, which may be due to basalt fiber concentration and increased fibre/matrix adhesion. Reinforcement fibers increase the fibre/matrix interfacial bonding and act as a barrier that restricts the mobility of chain segment; thus, reduction in damping factor occurs in rubbery region. The $\tan \delta$ peak

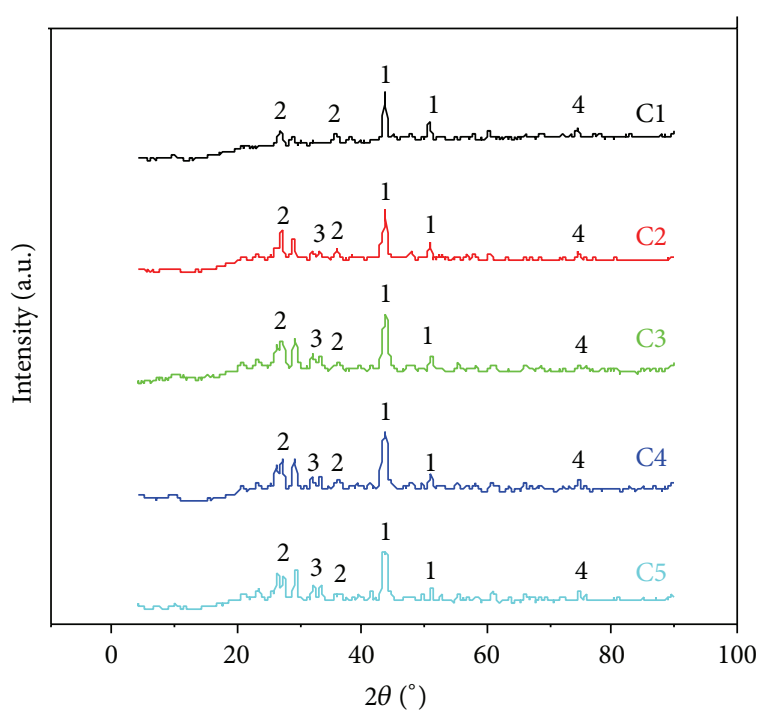
(1) $\mathrm{Cu}$
(2) $\mathrm{Al}_{2} \mathrm{O}_{3}$
(3) $\mathrm{BaSO}_{4}$
(4) $\mathrm{SiC}$

FIGURE 8: XRD patterns of hybrid friction composites.

height is least for composite $\mathrm{C} 1$ which confirms that with increase in wt $\%$ of basalt fiber, better fiber/matrix interfacial bonding occurs. It allows effective stress transfer from fiber to matrix and improved the load bearing properties of the composites.

4.2.4. Cole-Cole Plot. Figure 7 illustrates the Cole-Cole plot which is a tool to examine structural changes taking place in cross-linked polymers after the reinforcement of fibers into polymer matrix and it is valuable to measure the viscoelastic properties of polymers [29]. Cole-Cole plot is constructed as the variation in loss modulus with storage modulus and its semicircular nature indicates the degree of homogeneity of polymer composite [30]. The imperfect semicircular shape indicates the heterogeneity of system and good fibre/matrix bonding. It is evident that amount of fiber incorporation will change the shape of Cole-Cole plot. In this present study, all composites show imperfect semicircular curve suggestive of the heterogeneity of composite and relatively better fibre/matrix interfacial bonding. From Figure 7, it is also observed that with increase in weight fraction basalt from composite $\mathrm{C} 5$ to $\mathrm{C} 1$, the heterogeneity of the composite has also increased, thereby influencing dynamic mechanical properties of polymeric composites [9].

4.3. X-Ray Diffraction Analysis. The X-ray diffraction patterns of friction composites are shown in Figure 8. The patterns of composites were identified and $[h k l]$ values were indexed using the JCPDS-ICDD database (Joint Committee on Powder Diffraction Standards-International Centre for Diffraction Data, 2003). The peaks at diffraction angles $(2 \theta)$ between 25.6 and $75^{\circ}$ confirm the phase formation such as $\mathrm{Cu}, \mathrm{Al}_{2} \mathrm{O}_{3}, \mathrm{BaSO}_{4}$, and $\mathrm{SiC}$. The peaks [ $h k l$ plane] at $43.3^{\circ}(1$ 11 ) and $50.4^{\circ}(200)$ indicate the presence of $\mathrm{Cu}$ with cubic 


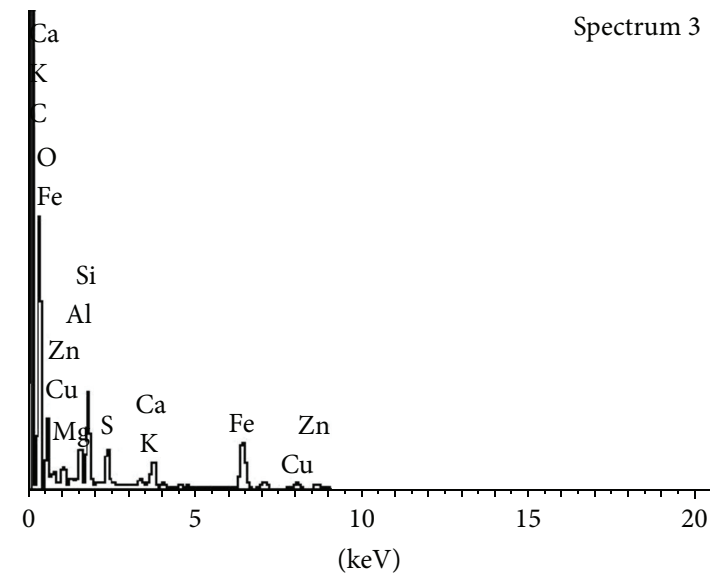

Full scale 2980 cts cursor: 0.000

(a)

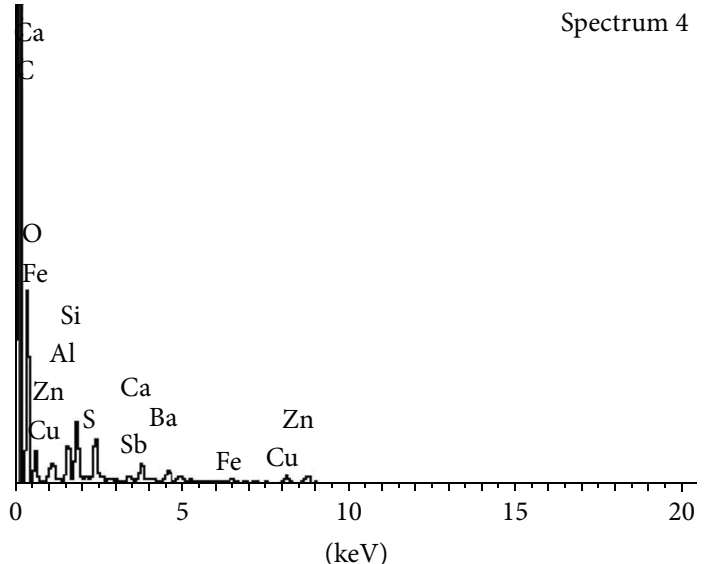

Full scale 2980 cts cursor: 0.000

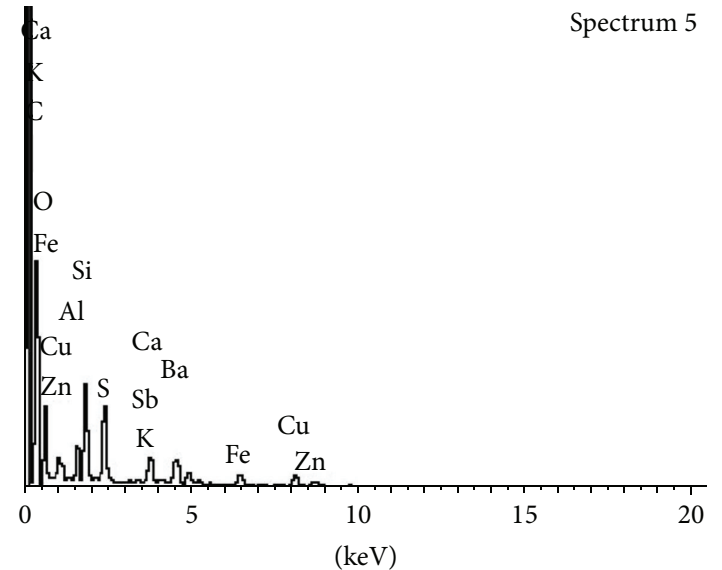

Full scale 2980 cts cursor: 0.000

(c)

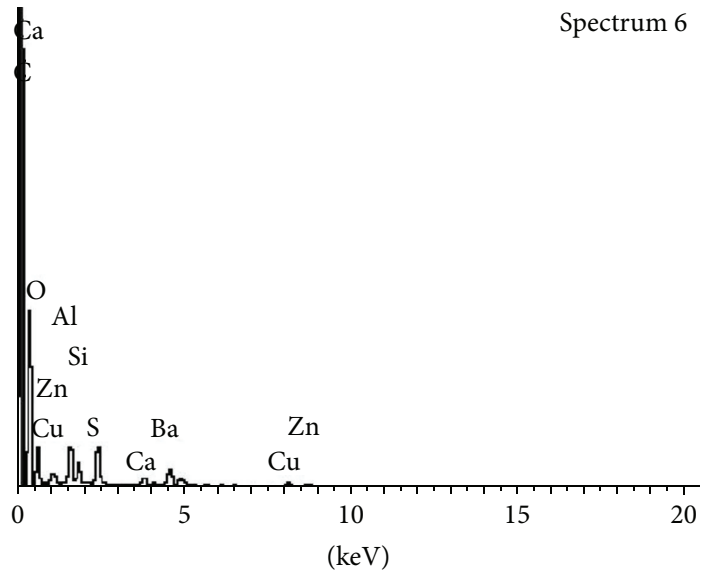

Full scale 2980 cts cursor: 0.000

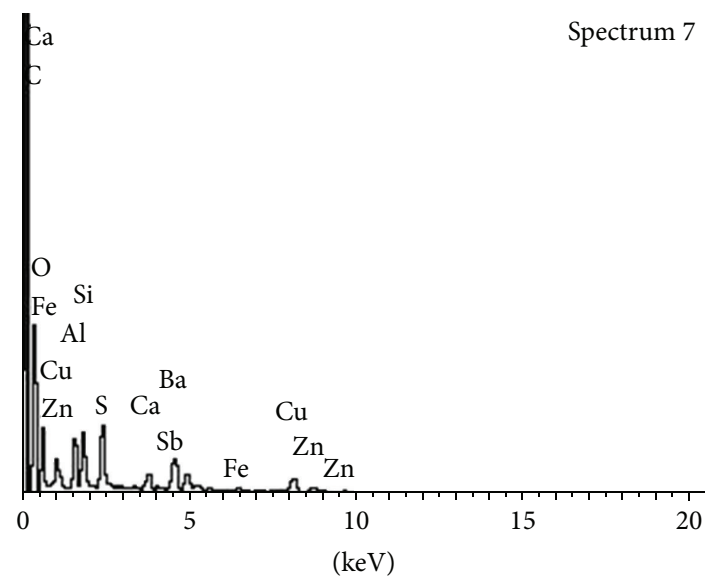

Full scale 2980 cts cursor: 0.000

(d)

(e)

FIGURE 9: EDX patterns of hybrid friction composites (C1-C5). 
structure. The minor peaks around $25.6^{\circ}\left(\begin{array}{lll}0 & 1 & 2\end{array}\right)$ and $35.2^{\circ}$

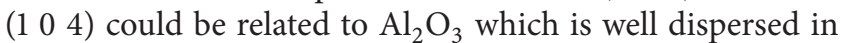
all composites with rhombohedral structure. The intensity of peaks at $2 \theta=32^{\circ}\left[\begin{array}{lll}3 & 0 & 1\end{array}\right]$ indicates the presence of $\mathrm{BaSO}_{4}$ filler and this peak increases with increase in filler content. However the absence of such peak in composite $\mathrm{C} 1$ confirms that $\mathrm{BaSO}_{4}$ is not used in this formulation. The XRD pattern displays minor peaks near $74.6^{\circ}$ could be attributed to the presence of $\mathrm{SiC}$ in friction composites.

4.4. Energy-Dispersive X-Ray Analysis. Table 4 shows the summary of elements detected in energy-dispersive X-ray (EDAX) analysis and the elements of phenolic composite are illustrated in Figures 9(a)-9(e) for friction composites. Spectral analysis detected higher number of elements in composite $\mathrm{C} 1$ than other composites. Presence of carbon (C) (63.09 wt\%) and oxygen (O) (19.14 wt\%) was found to be dominant as compared to other elements, iron (Fe) (6.71 wt\%), silica $(\mathrm{Si})(3.22 \mathrm{wt} \%)$, and copper $(\mathrm{Cu})(1.72 \mathrm{wt} \%)$. Carbon probably comes from the binder such as phenol formaldehyde resin and carbon powder. Iron is used in the form of iron powder and its content is comparatively more in $\mathrm{C} 1$ than other formulation and barium $(\mathrm{Ba})$ is not detected in composite $\mathrm{Cl}$ since barium sulphate is not used in this formulation.

In composite $\mathrm{C} 2$ carbon is still dominant and probably its content in $\mathrm{C} 2$ is equal to that of $\mathrm{C} 1$. The significant difference observed between composite $\mathrm{C} 1$ and other composites is the presence of magnesium $(\mathrm{Mg})$ in sample $\mathrm{C} 1$ which comes from higher volume $\%$ of basalt fiber. The weight $\%$ of alumina (Al), copper $(\mathrm{Cu})$, and barium $(\mathrm{Ba})$ in sample $\mathrm{C} 2$ tends to increase as compared to $\mathrm{Cl}$ and the content of iron $(\mathrm{Fe})$ is much lower in $\mathrm{C} 2$. The calcium $(\mathrm{Ca})$ element is well distributed in all composites of EDX spectrum which probably arrives from binder (plaster of paris).

Alumina is well dispersed in all samples which come from alumina filler. It is noted that in composite C3, weight \% of silica, sulphur, calcium, and copper are more or less equal to $\mathrm{C} 2$ but their peak heights are different. Barium $(\mathrm{Ba})$ and iron (Fe) contents are more in $\mathrm{C} 3$ compared to $\mathrm{C} 2$. The magnesium $(\mathrm{Mg})$ is not being detected except composite $\mathrm{Cl}$ may be due to the basalt fiber is not well distributed or less wt $\%$ is used in the formulation.

In composite $\mathrm{C} 4$, carbon is still the dominant element. Compared to other composites the weight \% of silica is less and sulphur and barium are more.

In composite C5 ten elements were detected. Carbon is still the dominant element but it attains lower weight $\%$ than other composites. Barium content is gradually increasing from composite $\mathrm{C} 2$ and reaches high weight \% in composite C5 which may be due to increase in the barium sulphate content which compensates basalt fiber during formulation. The weight $\%$ of $\mathrm{Al}, \mathrm{S}$, and $\mathrm{Cu}$ are high and iron is less when compared to other composites. Based on the elements detected in EDAX spectrum, the fabricated phenolic composites can be classified as a semimetallic type of phenolic composite material.
TABLE 4: Elemental composition of hybrid friction composites.

\begin{tabular}{lccccc}
\hline Element & $\mathrm{C} 1$ & $\mathrm{C} 2$ & $\mathrm{C} 3$ & $\mathrm{C} 4$ & $\mathrm{C} 5$ \\
\hline $\mathrm{C}$ & 63.1 & 60.1 & 56.5 & 61.6 & 48.9 \\
$\mathrm{O}$ & 19.1 & 16.8 & 21.6 & 19.2 & 21.2 \\
$\mathrm{Mg}$ & 0.25 & & & & \\
$\mathrm{Al}$ & 1.38 & 2.07 & 1.32 & 2.63 & 2.75 \\
$\mathrm{Si}$ & 3.22 & 3.4 & 3.5 & 1.63 & 2.88 \\
$\mathrm{~S}$ & 1.45 & 2.89 & 2.98 & 3.21 & 3.76 \\
$\mathrm{Ca}$ & 1.23 & 1.73 & 1.52 & 0.77 & 1.38 \\
$\mathrm{Fe}$ & 2.71 & 0.78 & 1.4 & 1.09 & 0.71 \\
$\mathrm{Cu}$ & 1.72 & 3.17 & 2.86 & 2.33 & 5.11 \\
$\mathrm{Zn}$ & 1.4 & 3.38 & 1.29 & 1.49 & 2.15 \\
$\mathrm{Ba}$ & & 4.1 & 5.57 & 7.23 & 9.77 \\
\hline
\end{tabular}

\section{Conclusions}

Positive correlation between thermomechanical properties of fabricated $\mathrm{f}$ phenolic composite with fiber reinforcement has been qualitatively emphasised. Hardness of phenolic composites was found to increase with increase in basalt fiber loading. The DMA results clearly reveal that sample $\mathrm{Cl}$ with high basalt fiber loading has got highest storage modulus and loss modulus values. Fiber incorporation decreases the damping properties of composite by acting as barrier to molecular chain movement. The shift in $T_{g}$ of phenol formaldehyde matrix with fiber reinforcement reveals that fibers play a significant role above $T_{g}$. XRD pattern exemplifies the presence of $\mathrm{Cu}, \mathrm{Al}_{2} \mathrm{O}_{3}, \mathrm{BaSO}_{4}$ and $\mathrm{SiC}$ with well-defined peaks. Based on the elements detected in EDAX spectrum, the fabricated friction composites can be classified as a semimetallic type of phenolic material.

\section{Conflict of Interests}

The authors declare that there is no conflict of interests with any financial organization regarding the material discussed in this paper.

\section{Acknowledgment}

The authors are thankful to the technical staffs at the Railway Workshop of South Western Railway, Mysore division, Karnataka, for their kind assistance to fabricate the hybrid phenolic composites.

\section{References}

[1] J. Bijwe, "Composites as friction materials: recent developments in non-asbestos fiber reinforced friction materials: a review," Polymer Composites, vol. 18, no. 3, pp. 378-396, 1997.

[2] D. Chan and G. W. Stachowiak, "Review of automotive brake friction materials," Journal of Automobile Engineering, vol. 218, no. 9, pp. 953-966, 2004.

[3] B. K. Satapathy and J. Bijwe, "Fade and recovery behavior of non-asbestos organic (NAO) composite friction materials based on combinations of rock fibers and organic fibers," 
Journal of Reinforced Plastics and Composites, vol. 24, no. 6, pp. 563-577, 2005.

[4] C. Tang and Y. Lu, "Combinatorial screening of ingredients for steel wool base semimetallic and aramid pulp based nonasbestos organic brake material," Journal of Reinforced Plastics and Composites, vol. 23, no. 1, pp. 51-63, 2004.

[5] B. Öztürk, F. Arslan, and S. Öztürk, "Hot wear properties of ceramic and basalt fiber reinforced hybrid friction materials," Tribology International, vol. 40, no. 1, pp. 37-48, 2007.

[6] W. K. Goertzen and M. R. Kessler, "Dynamic mechanical analysis of carbon/epoxy composites for structural pipeline repair," Composites Part B: Engineering, vol. 38, no. 1, pp. 1-9, 2007.

[7] V. G. Geethamma, G. Kalaprasad, G. Groeninckx, and S. Thomas, "Dynamic mechanical behavior of short coir fiber reinforced natural rubber composites," Composites A: Applied Science and Manufacturing, vol. 36, no. 11, pp. 1499-1506, 2005.

[8] K. Kumaresan, G. Chandramohan, M. Senthilkumar, and B. Suresha, "Dynamic mechanical analysis and three-body wear of carbon-epoxy composite filled with SiC particles," Journal of Reinforced Plastics and Composites, vol. 31, no. 21, pp. 1435-1448, 2012.

[9] M. S. Sreekala, S. Thomas, and G. Groeninckx, "Dynamic mechanical properties of oil palm fiber/phenol formaldehyde and oil palm fiber/glass hybrid phenol formaldehyde composites," Polymer Composites, vol. 26, no. 3, pp. 388-400, 2005.

[10] S. K. Waage, D. J. Gardner, and T. J. Elder, "Effects of fillers and extenders on the cure properties of phenol-formaldehyde resin as determined by the application of thermal techniques," Journal of Applied Polymer Science, vol. 42, no. 1, pp. 273-278, 1991.

[11] S. Wang, S. Adanur, and B. Z. Jang, "Mechanical and thermomechanical failure mechanism analysis of fiber/filler reinforced phenolic matrix composites," Composites B: Engineering, vol. 28, no. 3, pp. 215-231, 1997.

[12] K. C. M. Nair, S. Thomas, and G. Groeninckx, "Thermal and dynamic mechanical analysis of polystyrene composites reinforced with short sisal fibres," Composites Science and Technology, vol. 61, no. 16, pp. 2519-2529, 2001.

[13] A. K. Saha, S. Das, D. Bhatta, and B. C. Mitra, "Study of jute fiber reinforced polyester composites by dynamic mechanical analysis," Journal of Applied Polymer Science, vol. 71, no. 9, pp. 1505-1513, 1999.

[14] Y. Wu, M. Zeng, Q. Xu, S. Hou, H. Jin, and L. Fan, "Effects of glass-to-rubber transition of thermosetting resin matrix on the friction and wear properties of friction materials," Tribology International, vol. 54, pp. 51-57, 2012.

[15] R. P. Talegaonkar and K. Gopinath, "Influence of alumina fiber content on properties of non-asbestos organic brake friction material," Journal of Reinforced Plastics and Composites, vol. 28, no. 17, pp. 2069-2081, 2009.

[16] S. Joseph, S. P. Appukuttan, J. M. Kenny, D. Puglia, S. Thomas, and K. Joseph, "Dynamic mechanical properties of oil palm microfibril-reinforced natural rubber composites," Journal of Applied Polymer Science, vol. 117, no. 3, pp. 1298-1308, 2010.

[17] L. A. Pothan, S. Thomas, and G. Groeninckx, "The role of fibre/matrix interactions on the dynamic mechanical properties of chemically modified banana fibre/polyester composites," Composites A: Applied Science and Manufacturing, vol. 37, no. 9, pp. 1260-1269, 2006.

[18] M. Jacob, B. Francis, S. Thomas, and K. T. Varughese, "Dynamical mechanical analysis of sisal/oil palm hybrid fiber-reinforced natural rubber composites," Polymer Composites, vol. 27, no. 6, pp. 671-680, 2006.

[19] W. Stark, "Investigation of the curing behaviour of carbon fibre epoxy prepreg by Dynamic Mechanical Analysis DMA," Polymer Testing, vol. 32, no. 2, pp. 231-239, 2013.

[20] S. Keusch and R. Haessler, "Influence of surface treatment of glass fibres on the dynamic mechanical properties of epoxy resin composites," Composites A: Applied Science and Manufacturing, vol. 30, no. 8, pp. 997-1002, 1999.

[21] H. S. Jaggi, A. Tiwari, B. K. Satapathy, and A. Patnaik, "Dynamic mechanical response and fade-recovery performance of friction composites: effect of flyash and resin combination," Journal of Reinforced Plastics and Composites, vol. 32, no. 11, pp. 835-845, 2013.

[22] M. Jawaid, H. P. S. Abdul Khalil, and O. S. Alattas, "Woven hybrid biocomposites: dynamic mechanical and thermal properties," Composites A: Applied Science and Manufacturing, vol. 43, no. 2, pp. 288-293, 2012.

[23] M. Jawaid, H. P. S. Abdul Khalil, A. Hassan, R. Dungani, and A. Hadiyane, "Effect of jute fibre loading on tensile and dynamic mechanical properties of oil palm epoxy composites," Composites B: Engineering, vol. 45, no. 1, pp. 619-624, 2013.

[24] M. P. Sepe, Properties Measured by DMA. Dynamic Mechanical Analysis for Plastic Engineering, Plastics Design Library, New York, NY, USA, 1998.

[25] M. Akay, "Aspects of dynamic mechanical analysis in polymeric composites," Composites Science and Technology, vol. 47, no. 4, pp. 419-423, 1993.

[26] N. Hameed, P. A. Sreekumar, B. Francis, W. Yang, and S. Thomas, "Morphology, dynamic mechanical and thermal studies on poly(styrene-co-acrylonitrile) modified epoxy resin/glass fibre composites," Composites A: Applied Science and Manufacturing, vol. 38, no. 12, pp. 2422-2432, 2007.

[27] M. Botev, H. Betchev, D. Bikiaris, and C. Panayiotou, "Mechanical properties and visco elastic behaviour of basalt fiberreinforced polypropylene," Journal of Applied Polymer Science, vol. 74, no. 3, pp. 523-531, 1999.

[28] M. Jacob, B. Francis, K. T. Varughese, and S. Thomas, "The effect of silane coupling agents on the viscoelastic properties of rubber biocomposites," Macromolecular Materials and Engineering, vol. 291, no. 9, pp. 1119-1126, 2006.

[29] B. Harris, O. G. Braddell, D. P. Almond, C. Lefebvre, and J. Verbist, "Study of carbon fibre surface treatments by dynamic mechanical analysis," Journal of Materials Science, vol. 28, no. 12, pp. 3353-3366, 1993.

[30] M. Idicula, S. K. Malhotra, K. Joseph, and S. Thomas, "Dynamic mechanical analysis of randomly oriented intimately mixed short banana/sisal hybrid fibre reinforced polyester composites," Composites Science and Technology, vol. 65, no. 7-8, pp. 1077-1087, 2005. 

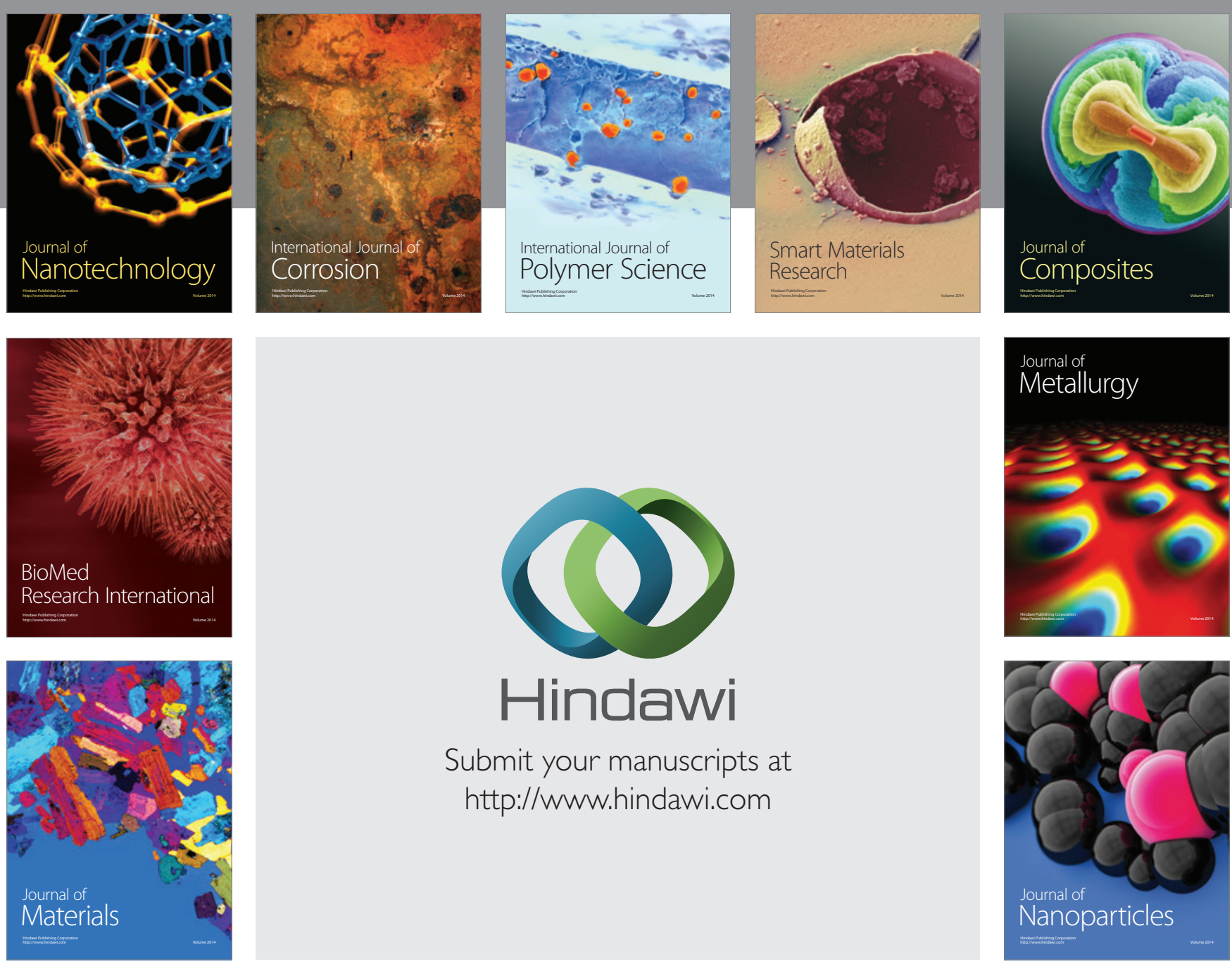

Submit your manuscripts at http://www.hindawi.com
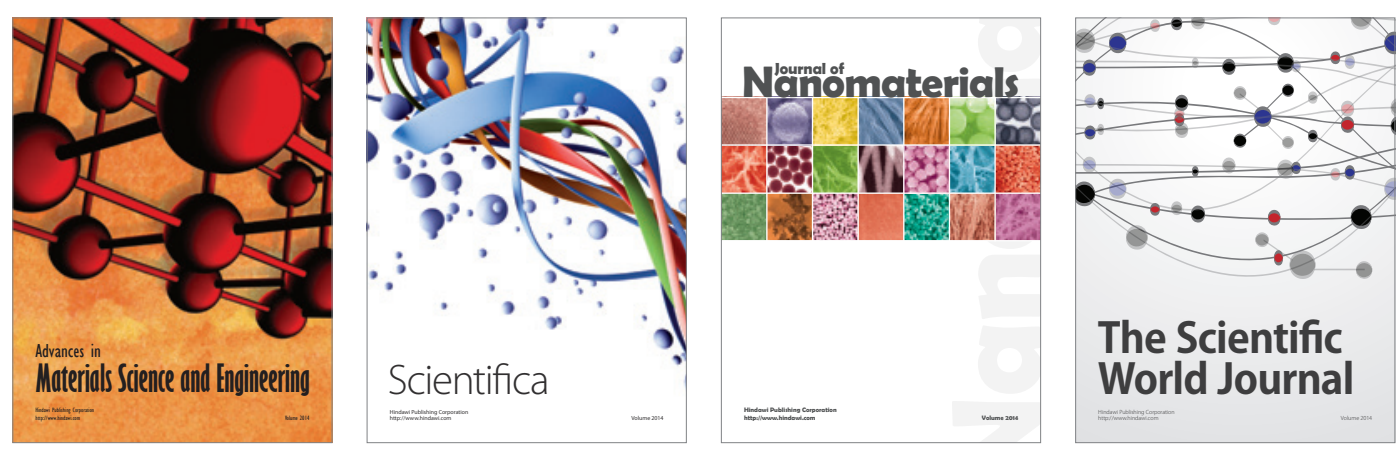

\section{The Scientific World Journal}
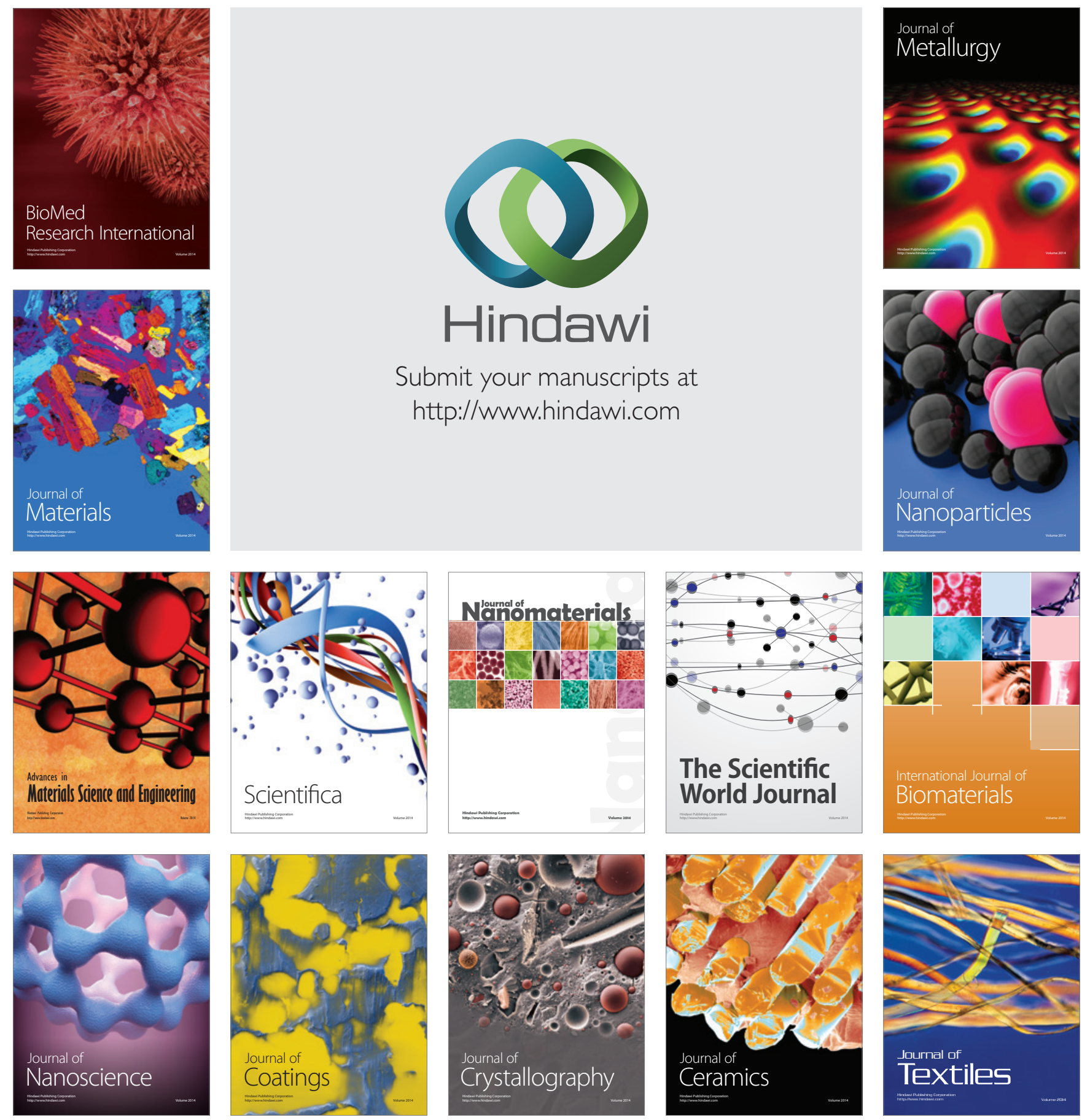